Mal J Nutr 25(2): 297-307, 2019

\title{
Demographic factors, food security, health-related quality of life and body weight status of adolescents in rural area in Mentakab, Pahang, Malaysia
}

\author{
Susanti Alie, Norhasmah Sulaiman*, Fadilah Mohd Nor \& Siti Farhana Mesbah \\ Department of Nutrition and Dietetics, Faculty of Medicine and Health Sciences, \\ Universiti Putra Malaysia, Selangor, Malaysia
}

\begin{abstract}
Introduction: Adequate, nutritive and safe foods are crucial for growth and healthy living. Adolescents are vulnerable to food insecurity. This study was aimed at determining the demographic factors, food security status, health-related quality of life (HRQOL) and body weight status of adolescents in Mentakab, Pahang, Malaysia. Methods: This study involved 160 households that comprised pairs of mothers and children aged 13-17 years. Face-to-face interviews were conducted with the mothers to assess their demographic and food security status (Radimer/Cornell Hunger and Food Insecurity Instrument). Meanwhile, the children answered a self-administered HRQOL questionnaire (Pediatric Quality of Life Inventory, PedsQL). Body weight and height were measured to obtain the body mass index (BMI). Results: About $48.8 \%$ of the adolescents were from households with food insecurity. The number of school-going siblings, occupation status of mother, occupation status of father, household income and house ownership status were predictors of food security status $(p<0.05)$. After controlling for covariates, the HRQOL score and BMI were higher in adolescents from food-secure households than adolescents from foodinsecure households $(p<0.01)$. Conclusion: The prevalence of food insecurity was high and multifactorial. Food insecurity was further associated with HRQOL and BMI. Food assistance programmes are recommended to directly alleviate food insecurity. Concurrently, monetary and educational aids are advocated to reduce the economic burden, especially in low-income households.
\end{abstract}

Keywords: Adolescents, food insecurity, health-related quality of life, Malaysia

\section{INTRODUCTION}

Adolescence is the second most rapid phase of human growth. It is a period of life with specific health and developmental needs. Adolescent is defined as any person aged 10-19 years. However, the age range has been extended to between 10 and 24 years because it corresponds more closely to adolescent growth
(Sawyer et al., 2018). Nutrition plays an important role in fulfilling the energy and nutrient requirements for growth and bodily functions in adolescents (Das et al., 2017). Therefore, food security is crucial to sustain active and healthy lives. According to the World Food Summit, food security occurs when all people at all times have physical and

\footnotetext{
*Corresponding author: Dr Norhasmah Sulaiman

Department of Nutrition and Dietetics, Faculty of Medicine and Health Sciences,

Universiti Putra Malaysia.

Tel: 03-89472461; Fax: 03-89426769; Email: norhasmah@upm.edu.my

doi: https://doi.org/10.31246/mjn-2019-0001
} 
economic access to sufficient, safe and nutritious food to meet their dietary needs and food preferences for active and healthy lives (WHO, 2012).

The prevalence of food insecurity varies among adolescents. Previous studies have found that about $70 \%$ of Mexican children and adolescents experienced some degree of food insecurity (Rodriguez et al., 2017). The prevalence of food insecurity among Korean middle school adolescents (1214 years old) and Korean high school adolescents (15-18 years old) were $11.1 \%$ and $16.8 \%$, respectively (Nakitto et al., 2017). A local study done by Roselawati et al. (2017) reported that the prevalence of food insecurity among adolescents aged 7-13 years in Kuantan, Pahang was $77.0 \%$. The prevalence was higher among those from the low socioeconomic status.

The literature has reported several demographic factors that affect food insecurity. Low income is the main predictor of food insecurity (Mohamadpour, Sharif \& Keysami, 2012; Wang et al., 2015; Roselawati et al., 2017). Low income contributes to the inability to provide adequate basic needs (such as food) for the household members. Further, large numbers of school-going children in a household are associated with food insecurity because clothing, footwear, books, and pocket money for school-goers contribute significantly to the expenditure of the household (Norhasmah et al., 2011). Likewise, residents of rented accommodation units are more likely to be food-insecure than those who live in their own houses. This is because rent payments limit the monetary resources (Sriram \& Tarasuk, 2016). Demographic and socio-economic factors are risk factors of food insecurity.

Food insecurity has been associated with many undesirable consequences, including poor nutritional status (Norhasmah et al., 2011; Nakitto et al.,
2017) and poor academic performance (Belachew et al., 2011). Food-insecure children were three times more likely to be stunted and two times to be underweight as compared to food-secure children (Naser et al., 2014). This might be due to the lower frequency of daily meal intake. Adolescents from poor were less likely to have breakfast than those from high and middle socio-economic backgrounds (Crawford et al., 2015). School absenteeism rates were shown to be significantly higher in food-insecure primary school adolescents than those from food-secure in Ethiopia (Tamiru et al., 2016). Food-insecure adolescents were probably unable attend school because of illness and/or lack of access to food.

In Malaysia, little is known about food insecurity and the health-related quality of life (HRQOL) among adolescents. To the best of our knowledge, there has been no local study on the association between food security and HRQOL in adolescents; there was only one study conducted on food security and HRQOL in women (Ihab et al., 2012). Only one local study on food-insecurity and nutritional status among children aged 7-13 years has been identified (Roselawati et al., 2017). Although numerous studies have examined the contribution of food security to body weight status, the findings on the association between food insecurity and body weight status was inconsistent. Therefore, this study of adolescents was aimed at (i) determining if there was an association between demographic factors and food security status, and (ii) at examining the differences in HRQOL and body mass index (BMI) based on food security status.

\section{MATERIALS AND METHODS}

This cross-sectional study was carried out in Mentakab, which is one of the 
sub-districts of the Temerloh district in the state of Pahang in Peninsular Malaysia. A list of residential areas in Mentakab was obtained from the Municipal Council of Temerloh, Pahang. Mentakab was chosen due to its larger population and household counts in the said list as compared to other subdistricts. Based on the list, Kampung Penak was chosen as the study location because it had the largest residential areas. There were three residential areas in Kampung Penak, namely the traditional village of Kampung Penak, Taman Sri Penak, and Taman Penak Perdana. Quota sampling was applied whereby the sampling ratio was $2: 4: 4$. The village of Kampung Penak had 100 households while Taman Sri Penak and Taman Penak Perdana had around 300 households each; 32 households (20\%) from the traditional village, as well as 64 households (40\%) from each of Taman Sri Penak and Taman Penak Perdana were recruited into this study.

The total sample size was determined using the $\mathrm{G}^{*}$ power 3.1.9.2 software (Faul et al., 2007). The odds ratio (OR) was obtained from Tamiru et al. (2016), who had found that household food insecurity increased the odds of absenteeism by 2.81 times. The calculated minimum sample size was 133 respondents. After adding $20 \%$ to the minimum sample size to account for drop-outs, it was decided to increase the sample size to 160 respondents. The mothers with their children (the latter aged 13-17 years) were recruited in pairs. Mothers with hearing problems or mutism and physically disabled adolescents were excluded.

Ethical approval for this study was obtained from the Ethics Committee for Research Involving Human Subjects, Universiti Putra Malaysia (JKEUPM). Written consent was obtained from the respondents prior to data collection.
Independent variables

A questionnaire, which contained questions on demographic background, food security status and HRQOL, was used to collect data. The demographic background and food security status parts were answered by the mother, while the HRQOL of the adolescents part was answered by the adolescents themselves. Demographic background questions were on the child's age, child's sex, mother's age, ethnicity, marital status (of caregiver or parents), household size, number of siblings, number of schoolgoing siblings, household income, per capita income, parental occupation status, parental education level and house ownership status.

Food security status was assessed using the Radimer/Cornell Hunger and Food Insecurity Instrument. This section contained ten items that measured the levels or severity of food insecurity, namely, food security, household food insecurity, individual or adult food insecurity and child hunger. The answers were considered to be positive if the responses were either "sometimes true" or "often true". Conversely, "not true" answers reflected negative responses. The households were categorised as food-secure when there were negative answers to all hunger and food insecurity items. Positive answers to one or more household item(s) (14) defined household food insecurity. Meanwhile, positive answers to one or more items concerning the adults (5-7) or items on the quality of children's diet (8) - in addition to negative answers to the items on the quantity of children's intake (9-10) - denoted individual food insecurity. Positive answers to the items on the children's quantity of food intake (9-10) indicated child hunger.

\section{Dependent variables}

The Pediatric Quality of Life Inventory (PedsQL) version 4.0 Generic Core 
Scales was used to measure the HRQOL of adolescents. The PedsQL consisted of 23 items with four different subscales, namely physical, emotional, social, and school functions. The items were rated based on a five-point Likert scale that ranged from 0 (never) to 4 (almost always). In terms of scoring, the items were reverse-scored and could be linearly transformed into a 0-100 scale. Therefore, higher scores indicated better HRQOL. The reverse items were transformed to $0-100$ as follows: $0=100$, $1=75,2=50,3=25$, and $4=0$.

The BMI of the adolescents was assessed by measuring their body weight and height. Body weight was measured by using the calibrated TANITA weighing scale and height by using the stadiometer mobile height (Seca 206). All measurements were taken three times to obtain the average reading. The BMI was calculated by dividing the body weight with the height square.

\section{Data analysis}

Data were analysed by using IBM's Statistical Package for Social Sciences (SPSS) version 20 and the Anthroplus WHO software was used particularly to determine the category of the BMI among adolescents. Descriptive analysis included percentages and frequencies for categorical data. Means and standard deviations were used to describe the continuous data. Binary logistic regression was used to determine the demographic predictors of the food security status. After controlling the covariates, a general linear model (GLM) was used to determine the differences in the HRQOL scores and BMI based on the food security status. In the GLM analysis, food security status was grouped into two groups namely food secure and food insecure. The covariates were determined based on the presence of significant relationships between the demographic factors with HRQOL and
BMI. The level of significance was set at $p<0.05$.

\section{RESULTS}

\section{Demographic background, food security status, HRQOL and BMI}

The mean $\pm \mathrm{SD}$ age of the adolescents was $14.9 \pm 1.4$ years, with $61.2 \%$ of them aged 13-15 years (Table 1). The mean maternal age was $40.4 \pm 4.5$ years, with half of the mothers $(51.8 \%)$ in the range of $30-39$ years. Over half $(59.5 \%)$ of the mothers and $15.0 \%$ of the fathers were unemployed. The mean household size, number of children, and school-going children of the households were $5 \pm 1$, $3 \pm 1$, and $3 \pm 1$, respectively. Over half of the respondents $(53.1 \%)$ lived in rented units. The mean monthly household and per capita incomes were RM2363 \pm 1102 and RM467 \pm 305.66 , respectively.

The prevalence of food insecurity in this study was $48.8 \%$. This figure encompassed $20.0 \%$ who had household food insecurity, $13.8 \%$ individual food insecurity and $15.0 \%$ child hunger. Based on Radimer/Cornell hunger scale, food security status could be divided into four categories namely food secure, household food insecure, individual food insecure and child hunger. Household food insecurity was related to food supply management and acquisition issue, while individual food insecurity was related to food consumption issues and the physiological sensation of hunger. Child hunger was the most severe household food insecurity problem and it was characterised by a decrease in the quantity of food consumed by the children. Child hunger only occurs after adults in the household and quality of the children's diet had been affected by household food insufficiency. The total mean HRQOL score among the adolescents was $61.29 \pm 18.08$, with the highest mean score noted in emotional functioning $(64.03 \pm 22.55)$ and the lowest 
Table 1. Characteristics of the adolescent participants in this study

\begin{tabular}{|c|c|c|c|}
\hline Characteristics & $n$ & $\%$ & Mean $\pm S D$ \\
\hline Age (Years) & & & $14.9 \pm 1.4$ \\
\hline $13-15$ & 98 & 61.2 & \\
\hline $16-17$ & 62 & 38.8 & \\
\hline \multicolumn{4}{|l|}{ Sex } \\
\hline Male & 85 & 53.1 & \\
\hline Female & 75 & 46.9 & \\
\hline \multicolumn{4}{|l|}{ Ethnicity } \\
\hline Bumiputera & 124 & 77.4 & \\
\hline Non-Bumiputera & 36 & 22.6 & \\
\hline Mother's Age (Years) & & & $40.4 \pm 4.5$ \\
\hline $30-39$ & 83 & 51.8 & \\
\hline $40-49$ & 70 & 43.8 & \\
\hline$\geq 50$ & 7 & 4.4 & \\
\hline Mother's educational level (Years) & & & $10.19 \pm 3.67$ \\
\hline No formal education & 5 & 3.0 & \\
\hline Primary education & 31 & 19.4 & \\
\hline Secondary education & 56 & 35.0 & \\
\hline Tertiary education & 68 & 42.6 & \\
\hline Father's educational level (Years) & & & $12.96 \pm 2.83$ \\
\hline No formal education & 2 & 1.2 & \\
\hline Primary education & 2 & 1.2 & \\
\hline Secondary education & 50 & 31.3 & \\
\hline Tertiary education & 106 & 66.3 & \\
\hline \multicolumn{4}{|l|}{ Mother's occupation status } \\
\hline Housewife/unemployed & 95 & 59.4 & \\
\hline Private & 17 & 10.6 & \\
\hline Government & 20 & 12.5 & \\
\hline Self-employed & 28 & 17.5 & \\
\hline \multicolumn{4}{|l|}{ Father's occupation status } \\
\hline Unemployed & 24 & 15.0 & \\
\hline Private & 39 & 24.3 & \\
\hline Government & 30 & 18.8 & \\
\hline Self-employed & 67 & 41.9 & \\
\hline \multicolumn{4}{|l|}{ Parents Marital Status } \\
\hline Married & 135 & 84.4 & \\
\hline Non-married & 25 & 15.6 & \\
\hline Household size & & & $5 \pm 1$ \\
\hline $1-5$ & 79 & 49.4 & \\
\hline $6-10$ & 80 & 50.0 & \\
\hline$\geq 11$ & 1 & 0.6 & \\
\hline Number of siblings & & & $3 \pm 1$ \\
\hline $1-3$ & 70 & 43.8 & \\
\hline $4-6$ & 78 & 48.8 & \\
\hline$\geq 7$ & 12 & 7.4 & \\
\hline Number of school-going siblings & & & $3 \pm 1$ \\
\hline $1-2$ & 51 & 31.9 & \\
\hline $3-4$ & 96 & 60.0 & \\
\hline$\geq 5$ & 13 & 8.1 & \\
\hline
\end{tabular}




\begin{tabular}{lccc}
\hline Characteristics & $n$ & $\%$ & Mean \pm SD \\
\hline House ownership status & & & \\
$\quad$ Own & 75 & 46.9 & \\
$\quad$ Rented & 85 & 53.1 & $2363.13 \pm 1102.70$ \\
Household income (RM) & 59 & 36.9 & \\
$\quad<1500$ & 101 & 63.1 & \\
$\quad \geq 1500$ & & & $467.00 \pm 305.66$ \\
Income per capita (RM) ${ }^{\dagger}$ & 33 & 20.6 & \\
$\quad \leq 210$ & 126 & 79.4 & \\
$\quad$ >210 & & & \\
Food Security Status & 82 & 51.2 & \\
$\quad$ Food secure & 32 & 20.0 & \\
$\quad$ Household food insecurity & 22 & 13.8 & \\
$\quad$ Individual food insecurity & 24 & 15.0 & \\
$\quad$ Child hunger & & & \\
Body Mass Index (BMI) & 1 & 0.6 & \\
$\quad$ Severely thin & 6 & 3.8 & \\
$\quad$ Thin & 126 & 78.8 & \\
$\quad$ Normal & 22 & 13.8 & \\
$\quad$ Overweight & 5 & 3.1 & \\
$\quad$ Obese & & & $61.29 \pm 18.14$ \\
HRQOL & & & \\
$\quad$ Physical functioning & & & \\
$\quad$ Emotional functioning & & & \\
$\quad$ Social functioning & & & \\
$\quad$ School functioning & & & \\
\hline
\end{tabular}

${ }^{\dagger}$ Per capita income poverty line in Malaysia is RM210 and below

mean score in physical functioning (58.81 \pm 21.13$)$. The total mean BMI was $20.01 \pm 3.14 \mathrm{~kg} / \mathrm{m}^{2}$ and $4.4 \%$ of them were categorised as thin and severely thin. The prevalence of the overweight and obesity among the adolescents was $16.9 \%$.

\section{Predictors of food security status}

In the adjusted analysis, the factors that remained significantly associated with food security status were household income, number of school going children, occupation status of the parents and house ownership status $(p<0.05)$ (Table 2). Adolescents from households with an income of below RM1500 were 12.6 times more likely to fall into the food insecure group than those who came from where the household income was RM1500 and above $(A O R=12.626,95 \%$
CI: 2.681, 59.458). Adolescents who had $\geq 4$ school going siblings increased the odds of being food insecure by tenfold than adolescents who had $<4$ school going siblings $(A O R=10.726$, 95\% CI: 1.241, 92.714). Furthermore, unemployed parents were 22 times more likely to experience food insecurity than parents who were in employment $(p<0.05)$. Living in rented property was 18 times more likely to result in food insecurity compared to those living in their own $(A O R=18.093,95 \% \mathrm{CI}: 3.770$, 86.848). A household income of below than RM1500, with >3 school-goers in the household, unemployed parents and living in a rent house were the predictors of food insecurity and contributed $63.5 \%$ to $84.7 \%$ of the variance in food insecurity. 
Table 2. Demographic factors and food security status ( $n=160)$

\begin{tabular}{|c|c|c|}
\hline Variables & Adjusted OR $(95 \% \mathrm{CI})$ & $p$ \\
\hline Household income (RM) & & $0.001^{* *}$ \\
\hline$<$ RM1500 & $12.626(2.681,59.458)$ & \\
\hline$\geq \mathrm{RM} 1500$ & $\operatorname{Ref}(1.00)$ & \\
\hline Number of school-going children & & $0.031^{*}$ \\
\hline$\leq 3$ & $(1.00)$ & \\
\hline$\geq 4$ & $10.726(1.241,92.714)$ & \\
\hline Occupational status of mother & & $0.001^{*}$ \\
\hline Employed & $\operatorname{Ref}(1.00)$ & \\
\hline Unemployed & $22.221(3.540,139.473)$ & \\
\hline Occupational status of father & & $0.012^{*}$ \\
\hline Employed & $\operatorname{Ref}(1.00)$ & \\
\hline Unemployed & $22.354(1.969,253.479)$ & \\
\hline Household size & & 0.051 \\
\hline $1-5$ & $\operatorname{Ref}(1.00)$ & \\
\hline$\geq 6$ & $8.391(0.995,70.789)$ & \\
\hline House ownership status & & $0.000^{* *}$ \\
\hline Own & $\operatorname{Ref}(1.00)$ & \\
\hline Rented & $18.093(3.770,86.848)$ & \\
\hline
\end{tabular}

*Significant at $p<0.05$

$* *$ Significant at $p<0.01$

Cox \& Snell $\mathrm{R}^{2}=0.635$, Nagelkerke $\mathrm{R}^{2}=0.847$

\section{HRQOL scores based on food security status}

The food-insecure group had significantly poorer HRQOL (42.13 \pm 10.51$)$ than the food-secure group (69.95 \pm 7.50$)$ after controlling for the covariates of maternal age, maternal and paternal years of schooling, household income, number of siblings, as well as number of schoolgoing siblings $(F=59.842, \quad p<0.001)$ (Table 3). Similarly, the physical and psychosocial functioning scores were higher in the food-secure group than those in the food insecure group after controlling for the same covariates $(p<0.001)$.

\section{BMI based on food security status}

Adolescents from food-insecure households had significant lower BMI $\left(18.68 \pm 2.01 \mathrm{~kg} / \mathrm{m}^{2}\right)$ than adolescents from food-secure households $\left(21.28 \pm 3.50 \mathrm{~kg} / \mathrm{m}^{2}\right)$, after controlling for demographic background factors, namely, monthly income, income per capita, number of children, years of schooling of mothers and fathers $(F=18.141, p<0.001)$ (Table 3).

\section{DISCUSSION}

The prevalence of household food insecurity in this study was lower at $48.8 \%$ compared to the $77.0 \%$ shown in the earlier local study on children aged 7-13 years (Roselawati et al., 2017). The study settings might explain the differences in the prevalence of food insecurity. The study by Roselawati et al. (2017) was conducted in Kuantan, Pahang which is categorised as urban area, while the current study took place in Mentakab, Pahang which is a rural area. Living in a rural area is associated with the low expenditure as the villagers cultivated home-grown vegetables and home-reared animals for food instead of buying from the markets (Roselawati 
Table 3. HRQOL and BMI based on food security status after controlling the demographic factors

\begin{tabular}{lcccc}
\hline & \multicolumn{2}{c}{ Mean \pm SD } & \multirow{2}{*}{ F-value } & p-value \\
\cline { 2 - 3 } & Food security & Food insecurity & & \\
\hline HRQOL $^{\dagger}$ & $69.95 \pm 7.50$ & $42.13 \pm 10.51$ & 59.842 & $0.000^{*}$ \\
Physical functioning & $23.84 \pm 3.42$ & $13.54 \pm 5.20$ & 29.597 & $0.000^{*}$ \\
Emotional functioning & $15.32 \pm 3.30$ & $10.17 \pm 4.10$ & 12.543 & $0.001^{*}$ \\
Social functioning & $15.10 \pm 2.56$ & $9.44 \pm 3.83$ & 29.153 & $0.000^{*}$ \\
School functioning & $15.70 \pm 2.79$ & $8.99 \pm 3.12$ & 26.578 & $0.000^{*}$ \\
BMI $\left(\mathrm{kg} / \mathrm{m}^{2}\right)^{\ddagger}$ & $21.28 \pm 3.50$ & $18.68 \pm 2.01$ & 18.141 & $0.000^{*}$ \\
\hline
\end{tabular}

${ }^{\dagger}$ GLM - adjusted for covariates - mother's age, years of schooling for mother, years of schooling for father, household income, number of sibling, and number of sibling going to school

₹GLM - adjusted for covariates - monthly income, income per capita, number of children, years of schooling of mother and father

* Significant at $p<0.001$

et al., 2017). Furthermore, the costs for items such as house rental in rural area were lower than in an urban area leaving less money for foods (Sriram \& Tarasuk, 2016). This may explain the lower prevalence of food insecurity that we found in our study.

This study has revealed that unemployment among the parents of adolescents was associated with food insecurity (Etana \& Tolossa, 2017). Furthermore, this study has confirmed the outcomes of previous studies where low monthly incomes were associated with food insecurity (Norhasmah et al., 2011; Mohamadpour et al., 2012; Wang et al., 2015). Unemployment and low incomes result in poverty and thus food insecurity (Etana \& Tolosa, 2017). This situation was exacerbated by the large household size, the large number of siblings and school-going children, and occupancy of rented units which increase household expenditures and cause problems in the fulfillment of the food and non-food needs (Norhasmah et al., 2011).

The total mean HRQOL score in this study $(61.29 \pm 18.08)$ was lower than the study by Husna et al. (2013)
$(78.50 \pm 13.48)$ that was done on secondary school adolescents in Kuala Lumpur. However, the setting of Husna et al. (2013) study was different from that of ours as it was conducted in the urban area of Kuala Lumpur. Living in rural settings negatively affects the physical HRQOL (Kurpas, Mroczek \& Bielska, 2014). It might be due to the inadequate physical facilities in the rural areas and the consequent negative perception of their environment by the adolescents. Food insecurity was associated with physical functioning, as individuals in food-insecure households were more likely to report fair, poor, or very poor health statuses with activity limitations as compared to individuals in food-secure households (Ihab et al., 2012; Chung et al., 2016). It was previously shown that food insecure students were less likely to participate in strenuous physical activity and sport team (Shanafelt et al., 2016). This may have been because food insecurity was associated with poor physical ability owing to poor nutritional status (i.e. deficiencies of essential nutrient and low-quality food intake) (Chung et al., 2016). Therefore, physical functioning 
among the adolescents in this study was lower among food-insecure group when compared with the food-secure group.

Food insecurity was associated with poor social and psychology functioning because the individuals from food insecure households were vulnerable to feelings of anxiety, helplessness, and loss of control besides having psychological impairment (Ihab et al., 2012; Shanafelt et al., 2016; Utter et al., 2018). Furthermore, economic circumstances such as financial hardship could disrupt the emotional state of the mothers, which brought about the poor social and psychology functioning. In addition, food insecurity was found to be associated with poor functioning in school. This finding was consistent with that of a previous study (Shanafelt et al., 2016) which documented that food-insecure students had lower grades or poor academic performance than food-secure students. Among the schooling children and adolescents, food insecurity was related with fewer family meals and skipping of breakfast. Breakfast has been reported to provide positive academic performance particularly in the memory and attention domains (Adolphus, Lawton \& Dye, 2013). Inadequate nutrient intake among the food-insecure individuals could reduce normal brain function (Palar et al., 2015).

In the context of the body weight status, the findings of this study contradicted that of the previous study of Roselawati et al. (2017), which found that there was no significant association between childhood obesity and food insecurity. The current study found that BMI was significantly lower in the food insecure group. Food insecurity was associated with inadequate food intake and low consumption of nutritious food (low intake of fruits and vegetables). Food insecure households might purchase low quality and quantity of food due to the limited income (Mohamadpour et al., 2012). Food-insecure individuals usually experienced skipping meals and consumed smaller portion sizes of meals which contributed to their low overall energy intake.

There were several limitations in this study. This was a cross-sectional study, so the cause-and-effect relationships could not be determined. Only an association could be established between the independent variables and dependent variables. Furthermore, this study did not explore other factors that were related to food security status. Instead, only demographic factors such as sex, ethnicity, parental education levels, parental occupation status, house ownership status, household size, number of school-going siblings, number of siblings, parental marital status and household income were included in this study. Besides, as this study merely focused on the adolescent population, the HRQOL findings could not be extrapolated to other populations such as the elderly.

\section{CONCLUSION}

In conclusion, nearly half of the households $(48.8 \%)$ suffered from some degree of food insecurity. Having $\geq 4$ school going children, unemployed parents and a household income of <RM1500 and living in a rented property were the main contributors of food insecurity. Furthermore, food insecurity was associated with poor HRQOL and low BMI. Food assistance programmes are recommended to alleviate the high prevalence of food insecurity. Monetary and school aids are also advocated to reduce the economic burden in households with low monthly incomes. Future local studies pertaining to the factors and consequences of food insecurity in adolescents are recommended. 


\section{Acknowledgement}

Our sincere appreciation goes towards all parties involved in this study, including Pejabat Penghulu Mentakab, the Munipical Council of Temerloh, and Universiti Putra Malaysia. We would also like to express our gratitude to the respondents for their participation in this study.

\section{Authors' contributions}

SA, conceptualised and designed the study, carried out the data collection and prepared the draft of the manuscript; NS, supervised the flow of the overall research and reviewed the manuscript; FMN and SFM assisted in the drafting and review of the manuscript.

\section{Conflict of interest}

The authors have no conflict of interest.

\section{References}

Adolphus K, Lawton CL \& Dye L (2013). The effects of breakfast on behavior and academic performance in children and adolescents. Front Hum Neurosci 7:425.

Belachew T, Hadley C, Lindstrom D, Gebremariam A, Lachat C \& Kolsteren P (2011). Food insecurity, school absenteeism and educational attainment of adolescents in Jimma Zone Southwest Ethiopia: a longitudinal study. Nutri $J$ 10:29.

Chung HK, Kim OY, Kwak SY, Cho Y, Lee KW \& Shin MJ (2016). Household food insecurity is associated with adverse mental health indicators and lower quality of life among Koreans: results from the Korea National Health and Nutrition Examination Survey 2012-2013. Nutrients 8(12):819.

Crawford B, Yamazaki R, Franke E, Amanatidis S, Ravulo J \& Torvaldsen S (2015). Is something better than nothing? Food insecurity and eating patterns of young people experiencing homelessness. Australian and New Zealand $J$ Publ Hlth 39(4):350-354.

Das JK, Salam RA, Thornburg KL, Prentice AM, Campisi S, Lassi ZS, Koletzko B \& Bhutta ZA (2017). Nutrition in adolescents: physiology, metabolism, and nutritional needs. Ann NY Acad Sci 1393(1):21-33.

Etana D \& Tolossa D (2017). Unemployment and food insecurity in Urban Ethiopia. Afr Dev Rev 29(1):56-68.

Faul F, Erdfelder E, Lang AG \& Buchner A (2007). G* Power 3: A flexible statistical power analysis program for the social, behavioral, and biomedical sciences. Behavior Research Methods 39(2): 175-191.
Husna AA, Siew YL, Chinna K, Wah YL \& April Camilla R (2013). Psychometric properties of the self-report Malay version of the Pediatric Quality of Life (PedsQL ${ }^{\mathrm{TM}}$ ) 4.0 Generic Core Scales among multiethnic Malaysian adolescents. J Am Diet Assoc 100(6):665-73.

Ihab AN, Rohana AJ, Manan WW, Suriati WW, Zalilah MS \& Rusli AM (2012). Food expenditure and diet diversity score are predictors of household food insecurity among low income households in rural district of Kelantan Malaysia. Pak J Nutr 11(10):869-875.

Kurpas D, Mroczek B \& Bielska (2014). Rural and urban disparities in quality of life and health-related behaviors among chronically ill patients. Rural Remote Health 14(2):1-14.

Mohamadpour M, Sharif ZM \& Keysami MA (2012). Food insecurity, health and nutritional status among sample of palm-plantation households in Malaysia. J Hlth Popul Nutr 30(3):291.

Nakitto M, Asano K, Choi I \& Yoon J (2017). Dietary intakes of adolescents from food insecure households: analysis of data from the 6th (2013-2015) Korea National Health and Nutrition Examination Survey. Nutr Res Pract 11(6):507-516.

Naser IA, Jalil R, Muda W, Manan W, Nik W, Suriati W \& Abdullah MR (2014). Association between household food insecurity and nutritional outcomes among children in Northeastern of Peninsular Malaysia. Nutr Res Pract 8(3):30411.

Norhasmah S, Zalilah MS, Rohana AJ, Mohd Nasir MT, Kandiah M \& Asnarulkhadi AS (2011). Validation of the Malaysian Coping Strategy Instrument to measure household food insecurity in Kelantan, Malaysia. Food Nutr Bull 32:354-364.

Palar K, Kushel M, Frongillo EA, Riley ED, Grede N, Bangsberg D \& Weiser SD (2015). Food insecurity is longitudinally associated with depressive symptoms among homeless and marginally-housed individuals living with HIV. AIDS Behav 19(8):1527-1534.

Rodríguez LA, Mundo-Rosas V, Méndez-GómezHumarán I, Pérez-Escamilla R \& ShamahLevy T (2017). Dietary quality and household food insecurity among Mexican children and adolescents. Matern Child Nutr 13(4):e12372.

Roselawati MY, Wan Azdie MAB, Aflah A, Jamalludin AR \& Zalilah MS (2017). Food insecurity status and childhood obesity in Kuantan, Pahang. IJAHS 1(2):56-71. 
Sawyer SM, Azzopardi PS, Wickremarathne D \& Patton GC (2018). The age of adolescence. Lancet Child Adolesc Hlth 2(3):223-228.

Shanafelt A, Hearst MO, Wang Q \& Nanney MS (2016). Food insecurity and rural adolescent personal health, home, and academic environments. J Sch Hlth 86(6):472-480.

Sriram U \& Tarasuk V (2016). Economic predictors of household food insecurity in Canadian metropolitan areas. J Hunger Environ Nutri 11(1):1-13.

Tamiru D, Argaw A, Gerbaba M, Ayana G, Nigussie A \& Belachew T (2016). Household food insecurity and its association with school absenteeism among primary school adolescents in Jimma zone, Ethiopia. BMC Publ Hlth 16(1):802.
Utter J, Izumi BT, Denny S, Fleming T \& Clark T (2018). Rising food security concerns among New Zealand adolescents and association with health and wellbeing. Kōtuitui: New Zealand $J$ Soc Sci Online 13(1):29-38.

Wang EA, McGinnis KA, Goulet J, Bryant K, Gibert C, Leaf DA, Mattocks K, Fiellin LE, Vogenthaler N, Justice AC \& Fiellin DA (2015). Food insecurity and health: data from the Veterans Aging Cohort Study. Publ Hlth Rep 130(3):261268.

WHO (2012). PMNCH knowledge summary \#19 food security and climate change. From https: / /www.who.int/pmnch/knowledge/ publications/summaries/ks19/en/ [Retrieved October 9 2012]. 